ISSN 0103-9954

\title{
EFEITO DO TEOR DE EXTRATIVOS NA RESISTÊNCIA NATURAL DE CINCO MADEIRAS AO ATAQUE DE CUPINS XILÓFAGOS
}

\author{
EFFECT OF EXTRACTIVE CONTENTS ON NATURAL RESISTANCE OF FIVE DIFFERENT \\ WOODS TO XILOPHAGAUS TERMITES ATTACK
}

\author{
Juarez Benigno Paes ${ }^{1}$ Sara Carolina Soares Guerra ${ }^{2}$ Luciana Ferreira da Silva ${ }^{3}$ \\ José Geraldo Lima de Oliveira ${ }^{4}$ Gilson Barbosa São Teago ${ }^{5}$
}

\begin{abstract}
RESUMO
Quando o homem deixou de ser nômade, teve de se adaptar às novas condições, passando a empregar a madeira para energia, instrumentos de caça e defesa e elementos construtivos diversos. Desde então, em função dos usos e do rápido crescimento, a importância da madeira vem se acentuando, principalmente porque sua exploração agride menos o ambiente quando comparada a outros materiais não renováveis. Embora existam várias pesquisas sobre Eucalyptus e Pinus, estudos com outras espécies são incipientes, principalmente quanto ao efeito dos extrativos na resistência natural das madeiras. Assim, o objetivo da pesquisa foi avaliar a influência do teor de extrativos na resistência natural das madeiras de Acacia mangium, Casuarina sp., Eucalyptus cloeziana, Corymbia torelliana e Tectona grandis ao térmita xilófago Nasutitermes corniger, espécie de ocorrência frequente em várias regiões no Brasil. De cada espécie foram retirados corpos de prova, com dimensões de 2,00 x 10,16 x 0,64 cm (radial x longitudinal x tangencial) em quatro posições no sentido medula-alburno (cerne interno, cerne intermediário, cerne externo e alburno). As madeiras foram expostas à ação dos cupins durante 45 dias em ensaio de preferência alimentar. Amostras não selecionadas para o ensaio com cupins foram transformadas em serragem e o teor de extrativos obtido ao empregar a fração que passou pela peneira de 40 e ficou retida na de 60 mesh. A resistência natural não esteve associada ao teor de extrativos presentes na madeira. A resistência das madeiras variou no sentido medula-alburno, com padrão variável para cada espécie. As madeiras mais resistentes foram Tectona grandis e Corymbia torelliana e a mais deteriorada a Acacia mangium.
\end{abstract}

Palavras-chave: extrativos; térmitas xilófagos; preferência alimentar.

\section{ABSTRACT}

When man stopped being nomadic, he had to adapt to new conditions, and started employing wood for energy, hunting and defense instruments and miscellaneous constructive elements. Since then, in the light of usages and rapid growth, the importance of wood has been increasing, primarily by their exploitation assaults less the environment when compared to other non-renewable materials. Although there are several

1 Engenheiro Florestal, Dr., Professor do Departamento de Ciências Florestais e da Madeira, Universidade Federal do Espírito Santo, Av. Governador Lindemberg, 316, Centro, CEP 29550-000, Jerônimo Monteiro (ES), Brasil. jbp2@uol.com.br

2 Engenheira Florestal, Msc., Universidade Federal do Espírito Santo, Alto Universitário, Guararema, Caixa Postal, 16, CEP 29500-000, Alegre (ES), Brasil. sarinhaguerra@hotmail.com

3 Engenheira Agrônoma, Msc., Programa de Pós-Graduação em Ciências Florestais, Universidade Federal do Espírito Santo, Av. Governador Lindemberg, 316, Centro, CEP 29550-000, Jerônimo Monteiro (ES), Brasil. lu.ferreira1@hotmail.com

4 Engenheiro Agrônomo, Msc., Departamento de Ciências Florestais e da Madeira, Universidade Federal do Espírito Santo, Av. Governador Lindemberg, 316, Centro, CEP 29550-000, Jerônimo Monteiro (ES), Brasil. josegeralol@yahoo.com.br

5 Engenheiro Agrônomo, Msc., Departamento de Ciências Florestais e da Madeira, Universidade Federal do Espírito Santo, Av. Governador Lindemberg, 316, Centro, CEP 29550-000, Jerônimo Monteiro (ES), Brasil. gilsonbar@hotmail.com

Recebido para publicação em 3/07/2011 e aceito em 4/12/2014 
researches about Eucalyptus and Pinus, but studies with other species are incipient mainly about the extractive effects on the wood natural resistance. Thus, this research aimed to assess the influence of extractive contents with the natural resistance of Acacia mangium, Casuarina sp. Eucalyptus cloeziana, Corymbia torelliana and Tectona grandis woods to Nasutitermes corniger xylophagous termite, species of frequent occurrence in several regions in Brazil. From each species, test samples were taken, with dimensions of $2.00 \times 10.16$ x 0.64 (radial x longitudinal x tangential) in four positions in the medulla-sapwood direction (internal core, intermediate core, outer core and sapwood). The woods were exposed to the action of termites for 45 days in a food preference assay. The samples not selected for the test with termites were turned into sawdust and the extractive contents were obtained by using the fraction which passed through the sieve 40 and was retained in 60 mesh. The natural resistance has not been linked to extractive levels present in the wood. The resistance of wood varied in medulla-sapwood direction, with default variable for each species. The more resistant timbers were Tectona grandis and Corymbia torelliana and the most deteriorated was Acacia mangium.

Keywords: extractives; xylophagous termites; food preference assay.

\section{INTRODUÇÃO}

A partir do momento que o homem deixou de ser nômade, passou a empregar a madeira para diversos fins, sendo esta, atualmente uma das fontes mais utilizadas para produção de energia, celulose e papel, material de construção para os meios urbano e rural e nas indústrias de painéis e de móveis. Evidenciando a importância da mesma como material renovável e mais acessível que as outras fontes de matéria-prima, sua exploração agride menos o ambiente quando comparada à extração de materiais não renováveis.

A madeira é constituída por celulose, lignina e hemicelulose, que constituem a parede celular, os demais compostos são denominados extrativos. Os extrativos são componentes que não fazem parte da constituição química da parede celular e inclui elevado número de compostos, como resinas, açúcares, ácidos graxos, taninos e outros compostos fenólicos, que podem ser extraídos em água ou solventes orgânicos (SILVÉRIO et al., 2006). Os extrativos são os responsáveis pela cor, odor e resistência ao apodrecimento e ao ataque de insetos. Além disto, influenciam nas propriedades da madeira como permeabilidade, densidade e dureza (PETTERSEN, 1984).

A resistência da madeira à deterioração é a capacidade inerente à espécie de resistir à ação de agentes deterioradores, incluindo os agentes biológicos, físicos e químicos (PAES, 2002). Geralmente existe uma grande diferença de resistência entre o cerne interno e o externo, sendo o interno menos resistente. No entanto, essa não é uma regra, e algumas espécies não apresentam este mesmo padrão de variação na resistência natural (FINDLAY, 1985).

O conhecimento da resistência natural é importante para recomendação do uso mais adequado, poupando gastos desnecessários com a substituição de peças e reduzindo os impactos ao meio ambiente (FARIAS SOBRINHO et al., 2005; PAES et al., 2008). A resistência é atribuída à presença de certas substâncias no lenho, como taninos e outras substâncias fenólicas complexas, que podem ser tóxicas a fungos e a insetos xilófagos. Em algumas espécies, apenas um composto químico é o responsável pela resistência, e em outras, vários componentes atuam de modo sinérgico, para garantir a madeira sua durabilidade natural (PAES et al., 2004).

Cupins são insetos sociais da ordem Isóptera, que contêm cerca de 2.750 espécies descritas no mundo. São conhecidos por sua importância econômica como pragas de madeira e de outros materiais celulósicos, têm atraído a atenção de muitos pesquisadores por serem insetos sociais, e assim, considerados mais evoluídos (CONSTANTINO, 1999). A espécie Nasutitermes corniger é frequente em várias regiões brasileiras, com ataque a estruturas de madeira empregadas nos meios rural e urbano.

Embora existam inúmeras pesquisas sobre os gêneros Eucalyptus e Pinus, estudos sobre outras espécies são incipientes, principalmente quanto à durabilidade natural da madeira e o efeito dos extrativos na resistência natural das madeiras a cupins xilófagos, surgindo assim o interesse pelo estudo do comportamento de diversas espécies, empregadas em reflorestamentos no Brasil, quanto a 
resistência da madeira contra o ataque de xilófagos.

A acácia (Acacia mangium) vem despertando a atenção dos pesquisadores pela rusticidade, rápido crescimento e por ser nitrificadora (VEIGA; CARVALHO; BRASIL, 2000). É nativa do estado de Queensland, na Austrália, além de outros países como Papua, Nova Guiné e ilhas de Irian Java e Molucas, na Indonésia. Para vários autores citados por Balieiro et al. (2004), é uma espécie que tem apresentado significativa capacidade de adaptação às condições edafoclimáticas brasileiras por se adaptar a uma ampla faixa de solos (pH 4,5 a 6,5), porém, pouco adaptada a solos calcários. Depois de estabelecida, pode suportar temperaturas mínimas entre 12 e $25^{\circ} \mathrm{C}$ e máximas entre 31 e $34^{\circ} \mathrm{C}$ e tolera bem solos com baixa concentração de nutrientes.

A madeira de acácia é empregada para produção de madeira serrada, celulose e lenha por causa da densidade de sua madeira $\left(0,65 \mathrm{~g} \mathrm{~cm}^{-3}\right)$ (BARBOSA, 2002). Além disto, a espécie possui aptidão para produção de mourões, construção civil e indústria moveleira (BALIEIRO et al., 2004), além de possibilitar a produção de carvão e outros produtos como chapas de fibras de média densidade (MDF), aglomerados e compensados (SCHIAVO; MARTINS, 2003).

Casuarina é o nome comum de várias espécies de árvores do gênero Casuarina. É originária da Indonésia e Austrália e se adapta a pleno sol. São árvores de grande porte, geralmente confundidas com Pinus. É uma espécie arbórea e rústica que chega a medir 20 metros de altura e diâmetro de até 0,8 metros, com facilidade de adaptação a solos e climas variados. Por causa da boa qualidade de sua madeira a espécie foi amplamente difundida pelo mundo, inclusive no Brasil, onde é empregada para construções diversas e finalidades energéticas (SILVA et al., 2008).

Segundo Hall et al. (1975) citados por Moura et al. (1993), o Eucalyptus cloeziana ocorre no Leste de Queensland, na Austrália, em altitudes variando de 70 a $900 \mathrm{~m}$, chegando a $55 \mathrm{~m}$ de altura e diâmetro de até dois metros. A espécie tem boa qualidade para a produção de carvão, tábuas, postes, mourões e uso na construção civil (ALMEIDA, 2006), podendo ser utilizada na fabricação de pisos, em função de suas propriedades de dureza e flexão estática (REMADE, 2007).

A espécie Corymbia torelliana é de ocorrência natural em Queensland, na região de Atherton, na Austrália, com altitudes variando de 100 até $1.000 \mathrm{~m}$ e precipitação anual média de
1.000 a $1.500 \mathrm{~mm}$ e temperatura máxima de $29^{\circ} \mathrm{C}$ e mínima que varia de 10 a $16^{\circ} \mathrm{C}$. Sua madeira é levemente pesada, de alta estabilidade dimensional e boa permeabilidade. No Brasil tem sido plantada de forma intensiva, porém, poucos são os trabalhos realizados com a espécie (REMADE, 2001).

A teca (Tectona grandis), pertencente à família Verbenaceae, é uma árvore de grande porte, nativa do continente Asiático e Índico (RONDON, 2006). Seu plantio no Brasil teve início na década de 1960, pela Empresa Cáceres Florestal S.A., Mato Grosso (TSUKAMOTO FILHO et al., 2003). Em função da variedade de ambientes aos quais ocorre, adaptou-se bem em locais com temperaturas médias de $24^{\circ} \mathrm{C}$ (EMBRAPA FLORESTAS, 2004). A madeira de teca possui o alburno claro e cerne marrom-vivo e brilhante, sendo utilizada para móveis, laminação, compensados, lenha e carvão. É uma madeira leve, de densidade média $( \pm 0,65 \mathrm{~g}$. $\mathrm{cm}^{-3}$ ), porém, apresenta boa resistência à tração $\mathrm{e}$ à flexão. É bastante estável e praticamente não empena, apresentando também boa durabilidade do cerne, causado pela presença de tectoquinona, um extrativo contido em suas células (ANGELI, 2003).

Esta pesquisa teve como objetivos avaliar a resistência das madeiras de Acacia mangium Willd., Casuarina sp., Eucalyptus cloeziana F. Muell., Corymbia torelliana K.D.Hill \& L.A.S. Johnson e Tectona grandis L.f. a cupins xilófagos da espécie Nasutitermes corniger em ensaio de preferência alimentar; verificar a variação da resistência das madeiras estudadas na direção medula-alburno; e relacionar a resistência da madeira com o teor de extrativos existente nas mesmas.

\section{MATERIAL E MÉTODOS}

\section{Espécies estudadas e preparo do material}

As madeiras estudadas foram obtidas no Laboratório de Usinagem da Madeira, Departamento de Ciências Florestais e da Madeira, Centro de Ciências Agrárias e Engenharias, Universidade Federal do Espírito Santo, localizado no Município de Jerônimo Monteiro, Espírito Santo (Tabela 1).

Das madeiras foram selecionadas tábuas (peças) que continham o cerne (medula) e alburno intactos, com comprimento, espessura e largura variáveis de acordo com a disponibilidade e necessidade para a confecção dos corpos de prova. Das peças foram obtidos corpos de prova com dimensões de $2,00 \times 10,16 \times 0,64 \mathrm{~cm}$ (radial x 
TABELA 1: Relação das espécies estudadas.

TABLE 1: List of the studied species.

\begin{tabular}{ll}
\hline \multicolumn{1}{c}{ Nome comum } & \multicolumn{1}{c}{ Nome científico } \\
\hline Acácia & Acacia mangium Willd. \\
Casuarina & Casuarina sp. \\
Eucalipto cloeziana & Eucalyptus cloeziana F. Muell. \\
Eucalipto toreliana & Corymbia torelliana K.D. Hill \& L.A.S. Johnson \\
Teca & Tectona grandis L.f. \\
\hline
\end{tabular}

longitudinal $\mathrm{x}$ tangencial) em quatro posições no sentido medula-alburno (1 - cerne interno, 2- cerne intermediário, 3 - cerne externo e 4 - alburno). As posições avaliadas foram retiradas nas pranchas de madeira, conforme demonstrado por Paes et al. (2007).

Para o experimento foram selecionados 10 corpos de prova livres de defeitos para cada espécie e posição, totalizando 40 amostras para cada espécie, além de amostras de Pinus sp., utilizadas como testemunhas, conforme indicações da "American Society for Testing and Materials"- ASTM D 3345 (2005). As amostras selecionadas foram lixadas para eliminação de defeitos e secas em estufa à temperatura de $103 \pm 2^{\circ} \mathrm{C}$, até atingirem massa constante, pesadas em balança de $0,01 \mathrm{~g}$ de precisão e destinadas à montagem do experimento.

\section{Ensaio de preferência alimentar}

Para a montagem do ensaio empregouse uma caixa com a capacidade de 1.000 litros, contendo uma camada de areia de pelo menos $10 \mathrm{~cm}$. A areia foi mantida úmida durante todo o experimento para evitar a morte dos cupins. A caixa foi apoiada sobre quatro paralelepípedos, dispostos dentro de bandejas de alumínio contendo água, para evitar a fuga dos cupins, segundo metodologia descrita por Paes et al. (2007) e Paes (2010). A areia dentro da caixa foi nivelada e demarcada a área para a fixação das amostras, com $50 \mathrm{~cm}$ de largura e 80 $\mathrm{cm}$ de comprimento. As amostras foram sorteadas para que ficassem distribuídas em delineamento de blocos casualizados, com 10 blocos (repetições) e seis tratamentos (cinco espécies e a testemunha). As amostras tiveram metade do seu comprimento fixado na areia, contendo $8 \mathrm{~cm}$ entre blocos, $7 \mathrm{~cm}$ entre tratamentos e as amostras foram dispostas lado a lado, no sentido medula-cerne (Figura 1).
A colônia de cupins (Nasutitermes corniger Motsch.) foi coletada nas proximidades de Jerônimo Monteiro - ES, em um mourão de cerca, conduzida para o laboratório, tendo sido apoiada em uma bandeja para suporte de tubetes, sustentada por dois tijolos de alvenaria, apoiados sobre a areia dentro da caixa. A escolha da espécie de cupins foi por causa de sua distribuição frequente em várias regiões do Brasil.

As amostras ficaram expostas à ação dos cupins durante 45 dias, em local, com temperatura variando de 17 a $28^{\circ} \mathrm{C}$ e umidade relativa de 70 a $80 \%$. Concluído o experimento, os corpos de prova

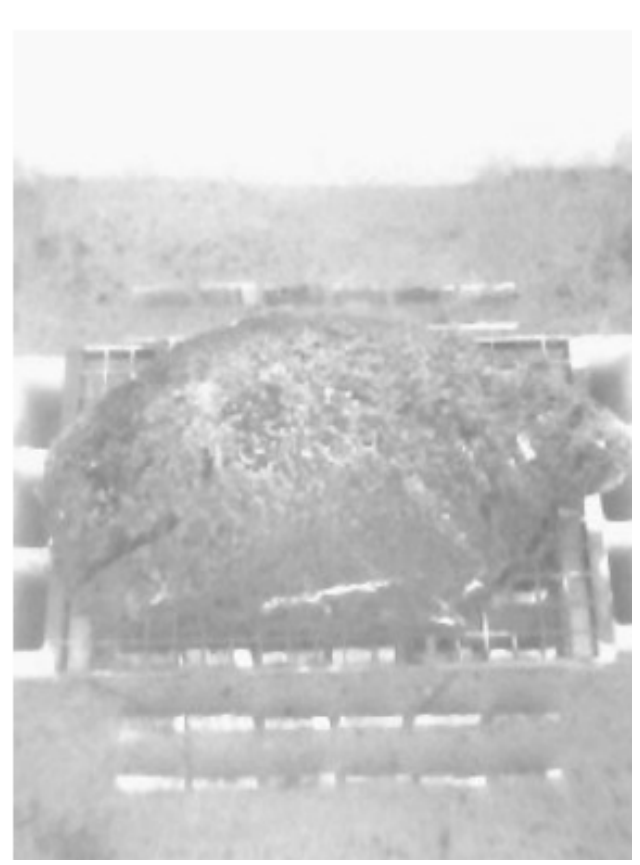

FIGURA 1: Disposição dos corpos de prova expostos à ação dos cupins (Nasutitermes corniger).

FIGURE 1: Disposal of test samples exposed to the action of termites (Nasutitermes corniger). 
TABELA 2: Avaliação do desgaste provocado pelos cupins nos corpos de prova (ASTMD 3345, 2005).

TABLE 2: Evaluation of waste caused by termites in test samples (ASTMD 3345, 2005).

\begin{tabular}{lc}
\multicolumn{1}{c}{ Tipos de desgaste } & Nota \\
\hline Sadio, permitindo escarificações superficiais & 10 \\
Ataque superficial & 9 \\
Ataque moderado, havendo penetração & 7 \\
Ataque intensivo & 4 \\
Falha, havendo ruptura dos corpos de prova & 0 \\
\hline
\end{tabular}

foram limpos com uma escova de cerdas macias, e secos em estufa a $103 \pm 2{ }^{\circ} \mathrm{C}$, até massa constante. Após a secagem, foi determinada a perda de massa em função do ataque dos cupins e o desgaste foi classificado segundo ASTMD 3345 (2005) (Tabela 2).

\section{Determinação do teor de extrativos}

As amostras não selecionadas para o ensaio com cupins foram transformadas em serragem e o teor de extrativos obtido ao empregar a fração que passou pela peneira de 40 e ficou retida na de 60 mesh. A serragem classificada foi climatizada à temperatura $20 \pm 2^{\circ} \mathrm{C}$ e $65 \pm 5 \%$ de umidade relativa.

$\mathrm{O}$ teor de extrativos da madeira foi determinado ao empregar uma solução de álcool/ tolueno $(2: 1 \mathrm{v} / \mathrm{v})$, com a utilização do aparelho tipo Soxhlet, conforme recomendações da M6/68 da Associação Técnica Brasileira de Celulose e Papel - ABTCP (1974). As análises químicas para a determinação dos extrativos foram realizadas em duplicatas.

Ao término de cada extração, os balões previamente pesados foram postos em estufa à temperatura de $103 \pm 2{ }^{\circ} \mathrm{C}$, até massa constante, pesados em uma balança de $0,001 \mathrm{~g}$ de precisão e por diferença de massa, determinado o teor de extrativos.

\section{Avaliação dos resultados}

Os teores de extrativos das madeiras nas posições estudadas foram avaliados ao utilizar um delineamento inteiramente casualizado com arranjo fatorial em que foram analisados os seguintes fatores: madeira, com cinco níveis, posição na direção medula-alburno, com quatro níveis e a interação entre os fatores.
Para comparar a resistência das madeiras, além dos valores apresentados na Tabela 2, foi empregado um delineamento em blocos casualizados, com arranjo fatorial, em que foram analisados os seguintes fatores: madeira, com seis níveis, posição na direção medula-alburno, com quatro níveis e a interação entre os fatores.

Para possibilitar a análise estatística, os dados de perda de massa foram transformados em arcsen [raiz quadrada (perda de massa/100)] e os do desgaste em raiz quadrada (nota $+0,5$ ). Estas transformações, sugeridas por Steel e Torrie (1980), foram necessárias para permitir a homogeneidade das variâncias. Na análise e avaliação dos ensaios foi empregado o teste de Scott-Knott $(\mathrm{p} \leq 0,05)$, para os fatores e interações detectados como significativos pelo teste de $\mathrm{F}(\mathrm{p} \leq 0,05)$.

\section{RESULTADOS E DISCUSSÃO}

$\mathrm{Na}$ Tabela 3, percebe-se que os valores de perda de massa, desgaste e teor de extrativos variaram entre as espécies e dentro de cada espécie. Ao serem analisados os valores de perda de massa, desgaste e os teores de extrativos, nota-se que a resistência natural da madeira a cupins xilófagos sofreu influência dos extrativos, sem estar associado, diretamente ao seu conteúdo, ou seja, madeiras com maiores teores de extrativos nem sempre foram as mais resistentes ao cupim testado, indicando que a resistência biológica da madeira está associada, além da quantidade, ao tipo e classe dos extrativos (FINDLAY, 1985). Paes et al. (2013) observaram que a resistência da madeira a cupins não esteve relacionada ao teor de extrativos, e sim à quantidade de cinzas existente na madeira.

A análise dos dados indicou que a madeira de teca foi a que apresentou maior resistência em relação ao ataque dos cupins, sofrendo a menor 
TABELA 3: Valores médios da perda de massa, desgaste e teor de extrativos obtidos nas quatro posições das espécies ensaiadas.

TABLE 3: Average values of loss of mass, waste and extractive contents obtained in four positions of tested species.

\begin{tabular}{|c|c|c|c|c|}
\hline Espécies & Posições & Perda de Massa $(\%)$ & Desgaste (Nota) & Teor de Extrativos (\%) \\
\hline \multirow{4}{*}{1 - Acácia } & 1 - Cerne Interno & 34,65 & 7,04 & 8,01 \\
\hline & 2 - Cerne Intermediário & 45,96 & 5,64 & 6,51 \\
\hline & 3 - Cerne Externo & 49,52 & 4,90 & 9,88 \\
\hline & 4 - Alburno & 28,91 & 5,44 & 5,92 \\
\hline \multirow{4}{*}{2 - Casuarina } & 1 - Cerne Interno & 17,52 & 8,64 & 7,14 \\
\hline & 2 - Cerne Intermediário & 16,32 & 9,20 & 10,47 \\
\hline & 3 - Cerne Externo & 14,52 & 9,54 & 4,11 \\
\hline & 4 - Alburno & 22,91 & 6,82 & 1,33 \\
\hline \multirow{4}{*}{3 - E. cloeziana } & 1 - Cerne Interno & 43,84 & 4,70 & 4,41 \\
\hline & 2 - Cerne Intermediário & 16,80 & 8,52 & 5,50 \\
\hline & 3 - Cerne Externo & 13,99 & 9,17 & 6,27 \\
\hline & 4 - Alburno & 14,42 & 8,50 & 2,16 \\
\hline \multirow{4}{*}{4 - Teca } & 1 - Cerne Interno & 11,76 & 10,00 & 8,87 \\
\hline & 2 - Cerne Intermediário & 11,97 & 10,00 & 8,79 \\
\hline & 3 - Cerne Externo & 12,52 & 10,00 & 9,48 \\
\hline & 4 - Alburno & 17,96 & 7,92 & 5,31 \\
\hline \multirow{4}{*}{5 - E. toreliana } & 1 - Cerne Interno & 19,98 & 6,36 & 3,49 \\
\hline & 2 - Cerne Intermediário & 21,17 & 7,46 & 6,37 \\
\hline & 3 - Cerne Externo & 24,38 & 7,46 & 4,19 \\
\hline & 4 - Alburno & 25,41 & 8,22 & 1,60 \\
\hline
\end{tabular}

perda de massa, seguida pela madeira de eucalipto toreliana. Os valores de perda de massa (\%) que deram origem à Tabela 3 foram analisados estatisticamente (Tabela 4).

Observa-se na Tabela 4 que houve diferença significativa entre blocos, espécies e para a interação posição $\mathrm{x}$ espécie. Não houve variação na forma como a madeira foi atacada, entre as posições, para as espécies avaliadas. As médias dos fatores bloco, espécie e da interação entre posição e espécie foram comparadas pelo teste de Scott-Knott $(\mathrm{p} \leq 0,05)$ e apresentadas na Tabela 5 .

Na Tabela 5, nota-se que casuarina, teca, eucalipto toreliana e Pinus não apresentaram diferenças significativas na perda de massa entre as posições na madeira. Por outro lado, a resistência natural das madeiras de acácia e eucalipto cloeziana foram afetadas pela posição em que foi obtida a amostra, tendo a madeira proveniente do cerne intermediário e externo da acácia sido menos resistente que a do cerne interno e alburno e para o eucalipto cloeziana, a madeira menos resistente foi a proveniente do cerne interno. A variação na resistência da madeira a cupins entre as posições analisadas foi observada por Paes e Vital (2000) e Paes et al. (2007), e atribuída à diferença na concentração de extrativos na madeira.

Com relação à resistência das espécies para cada posição no tronco (Tabela 5), observa-se que o eucalipto cloeziana e a acácia foram as espécies que tiveram a madeira proveniente do cerne interno mais consumida, quando comparada às demais espécies. Para o cerne intermediário e cerne externo, a madeira de acácia foi a mais susceptíveis, seguida pelo eucalipto toreliana. As madeiras provenientes do alburno de acácia, casuarina e eucalipto toreliana foram as mais atacadas pelos térmitas.

Dentre as madeiras analisadas, a acácia e 
TABELA 4: Análise de variância da perda de massa (\%) sofrida pelo ataque dos cupins nas madeiras ensaiadas. Dados transformados em arcsen [raiz quadrada (perda de massa/100)].

TABELA 4: Variance analysis of loss of mass (\%) suffered by termite attack in tested woods. Transformed data on arcsine [square root (loss of mass/100)].

\begin{tabular}{lcccc}
\hline Fonte de Variação & Grau de Liberdade & Soma de Quadrado & Quadro Médio & F \\
\hline Bloco & 9 & 0,55 & 0,61 & $5,16^{*}$ \\
Posição & 3 & 0,36 & 0,12 & $1,01^{\mathrm{ns}}$ \\
Espécie & 5 & 2,36 & 0,47 & $40,23^{*}$ \\
Posição x Espécie & 15 & 1,21 & 0,81 & $6,89^{*}$ \\
Resíduo & 207 & 2,43 & 0,12 & \\
\hline Total & 239 & 6,91 & & \\
\hline
\end{tabular}

Em que: * Significativo a $5 \%(0,01<\mathrm{p} \geq 0,05)$; ${ }^{\text {ns }}$ Não significativo a $5 \%(\mathrm{p}>0,05)$ pelo teste de $\mathrm{F}$.

TABELA 5: Valores médios de perdas de massa (\%) provocadas pelos cupins para as espécies e posições nas peças.

TABLE 5: Average values of mass loss (\%) caused by termites to species and positions in pieces.

\begin{tabular}{lcccc}
\hline \multirow{2}{*}{ Espécies } & \multicolumn{4}{c}{ Posições nas peças } \\
\cline { 2 - 5 } & 1 - Cerne Interno & 2 - Cerne Intermediário & 3 - Cerne Externo & 4 - Alburno \\
\hline 2 - Acácia & $34,65 \mathrm{Ba}$ & $45,96 \mathrm{Aa}$ & $49,52 \mathrm{Aa}$ & $28,91 \mathrm{Ba}$ \\
1 - Casuarina & $17,52 \mathrm{Ab}$ & $16,32 \mathrm{Ab}$ & $14,52 \mathrm{Ac}$ & $22,91 \mathrm{Aa}$ \\
3 - E. cloeziana & $43,84 \mathrm{Aa}$ & $16,80 \mathrm{Bb}$ & $13,99 \mathrm{Bc}$ & $14,42 \mathrm{Bb}$ \\
5 - Teca & $11,76 \mathrm{Ab}$ & $11,97 \mathrm{Ab}$ & $12,52 \mathrm{Ac}$ & $17,96 \mathrm{Ab}$ \\
4 - E. toreliana & $19,98 \mathrm{Ab}$ & $21,17 \mathrm{Ab}$ & $24,38 \mathrm{Ab}$ & $25,41 \mathrm{Aa}$ \\
6 - Pinus & $14,55 \mathrm{Ab}$ & $15,85 \mathrm{Ab}$ & $15,98 \mathrm{Ac}$ & $13,89 \mathrm{Ab}$ \\
\hline
\end{tabular}

Em que: As médias seguidas por uma mesma letra maiúscula, na horizontal, ou minúscula, na vertical, não diferem entre si (Scott-Knott; $p>0,05$ ).

o eucalipto toreliana foram aquelas que figuraram entre as mais atacadas para a maioria das posições avaliadas (posições 2; 3 e 4), enquanto a teca foi uma das madeiras mais resistente aos térmitas. A madeira de Pinus empregada como testemunha, por recomendações da ASTM D 3345 (2005), foi uma das espécies menos consumidas pelos térmitas. Paes e Vital (2000) e Paes et al. (2007) também observaram que cupins do gênero Nasutitermes consomem pouco a madeira de Pinus e atribuíram este fato à falta de hábito de ataque dos mesmos, uma vez que esta madeira é pouco empregada em situações em que ocorre, com frequência, o ataque de cupins de solo.

Observou-se que houve diferença significativa entre os blocos (Tabela 4). As médias foram analisadas e constam na Tabela 6. Observa-se que as madeiras dispostas nos blocos 3 e 5 foram mais consumidas que as demais. Isto pode ser atribuído ao modo como os cupins descem e atacam os corpos de prova, consumindo mais as madeiras com as quais tiveram o primeiro contato.

Na Tabela 7 consta a análise estatística da avaliação do desgaste sofrido pelas amostras. Notase que os fatores bloco, espécie e a interação entre posição e espécie causaram efeito significativo no desgaste da madeira. A influência dos blocos não foi analisada em termos de comparação entre médias, pois as causas foram as mesmas discutidas anteriormente para a perda de massa. A interação foi desdobrada e as médias do desgaste (nota) comparadas pelo teste de Scott-Knott a 5\% de probabilidade (Tabela 8 ).

As espécies acácia, eucalipto toreliana e Pinus não tiveram desgaste diferenciado entre as posições avaliadas. A casuarina e a teca apresentaram o alburno (posição 4) mais deteriorado que o cerne. No entanto, o eucalipto cloeziana teve as amostras 
TABELA 6: Perdas de massa provocadas pelos cupins em função da disposição dos blocos.

TABLE 6: Loss of mass caused by termites in function of disposition of blocks.

\begin{tabular}{cccc}
\hline Bloco & Perda de Massa (\%) & Bloco & Perda de Massa (\%) \\
\hline 1 & $19,69 \mathrm{~b}$ & 6 & $22,80 \mathrm{~b}$ \\
2 & $18,60 \mathrm{~b}$ & 7 & $21,22 \mathrm{~b}$ \\
3 & $30,17 \mathrm{a}$ & 8 & $21,30 \mathrm{~b}$ \\
4 & $17,21 \mathrm{~b}$ & 9 & $21,22 \mathrm{~b}$ \\
5 & $28,76 \mathrm{a}$ & 10 & $17,50 \mathrm{~b}$ \\
\hline
\end{tabular}

Em que: As médias seguidas por uma mesma letra não diferem entre si (Scott-Knott; $p>0,05$ ).

TABELA 7: Análise de variância do desgaste (nota) sofrida pelo ataque dos cupins nas madeiras ensaiadas. Dados transformados em raiz quadrada (nota $+0,5$ ).

TABLE 7: Variance analysis of waste (note) suffered by termite attack in tested woods. Transformed data on square root (note +0.5 )

\begin{tabular}{lcccc}
\hline \multicolumn{1}{c}{ Fonte de Variação } & Grau de Liberdade & Soma de Quadrado & Quadrado Médio & $\mathrm{F}$ \\
\hline Bloco & 9 & 209,49 & 23,28 & $5,23^{*}$ \\
Posição & 3 & 26,97 & 8,99 & $2,02^{\text {ns }}$ \\
Espécie & 5 & 329,17 & 65,83 & $14,80^{*}$ \\
Posição x espécie & 15 & 217,24 & 14,48 & $3,26^{*}$ \\
Resíduo & 207 & 920,72 & 4,45 & \\
\hline Total & 239 & 1703,59 & \\
Em que: * Significativo a 5\% $(0,01<\mathrm{p} \geq 0,05) ;{ }^{\text {ns }}$ Não-significativo a 5\% $(\mathrm{p}>0,05)$ pelo teste de F.
\end{tabular}

TABELA 8: Médias do desgaste (nota) causado pelos cupins para as espécie e posições nas peças. TABLE 8: Averages of waste (note) caused by termites to species and positions in pieces.

\begin{tabular}{lcccc}
\hline \multirow{2}{*}{ Espécies } & \multicolumn{4}{c}{ Posição na peça } \\
\cline { 2 - 5 } & 1 - Cerne Interno & 2 - Cerne Intermediário & 3 - Cerne Externo & 4 - Alburno \\
\hline 1 - Acácia & $7,04 \mathrm{Ab}$ & $5,64 \mathrm{Ab}$ & $4,90 \mathrm{Ab}$ & $5,44 \mathrm{Ab}$ \\
2 - Casuarina & $8,64 \mathrm{Aa}$ & $9,20 \mathrm{Aa}$ & $9,54 \mathrm{Aa}$ & $6,82 \mathrm{Bb}$ \\
3 - E. cloeziana & $4,70 \mathrm{Bc}$ & $8,52 \mathrm{Aa}$ & $9,17 \mathrm{Aa}$ & $8,50 \mathrm{Aa}$ \\
4 - Teca & $10,00 \mathrm{Aa}$ & $10,00 \mathrm{Aa}$ & $10,00 \mathrm{Aa}$ & $7,92 \mathrm{Ba}$ \\
5 - E. toreliana & $6,36 \mathrm{Ab}$ & $7,46 \mathrm{Ab}$ & $7,46 \mathrm{Aa}$ & $8,22 \mathrm{Aa}$ \\
6 - Pinus & $8,58 \mathrm{Aa}$ & $8,54 \mathrm{Aa}$ & $8,42 \mathrm{Aa}$ & $8,59 \mathrm{Aa}$ \\
\hline
\end{tabular}

Em que: As médias seguidas por uma mesma letra maiúscula, na horizontal, ou minúscula, na vertical, não diferem entre si (Scott-Knott; $p>0,05)$.

provenientes do cerne interno, mais consumidas que as demais posições. Paes e Vital (2000) ao avaliarem a resistência natural de sete espécies de eucalipto a cupins do gênero Nasutitermes notaram que algumas das espécies analisadas tiveram o cerne interno mais atacado pelos cupins e atribuíram tal fato à presença de lenho juvenil nos mesmos.
A análise da resistência ao ataque do térmita para cada posição nas madeiras revelou que as madeiras de teca e casuarina apresentaram o cerne interno mais resistente que as demais, e o eucalipto cloeziana foi a espécie mais deteriorada. Para a posição 2 (cerne intermediário), a acácia e o eucalipto toreliana foram as espécies mais 
TABELA 9: Análise de variância do teor de extrativos (\%) nas madeiras ensaiadas. Dados transformados em arcsen [raiz quadrada (extrativos/100)].

TABELA 9: Variance analysis of extractive contents (\%) in tested woods. Transformed data on arcsine [square root (extractives/100)].

\begin{tabular}{lcccc}
\hline \multicolumn{1}{c}{ Fonte de Variação } & Grau de Liberdade & Soma de Quadrados & Quadrado Médio & $\mathrm{F}$ \\
\hline Posição & 3 & $0,60 \times 10^{-1}$ & $0,20 \times 10^{-1}$ & $419,00 * *$ \\
Espécie & 4 & $0,52 \times 10^{-1}$ & $0,13 \times 10^{-1}$ & $277,55 * *$ \\
Posição x Espécie & 12 & $0,31 \times 10^{-1}$ & $0,26 \times 10^{-2}$ & $53,87 * *$ \\
Resíduo & 20 & $0,95 \times 10^{-3}$ & $0,48 \times 10^{-4}$ & \\
\hline Total & 39 & & &
\end{tabular}

Em que: **Significativo a $1 \%(\mathrm{p} \leq 0,01)$.

TABELA 10: Teores de extrativos nas espécies e posições nas peças.

TABLE 10: Extractive contents on the species and positions in pieces.

\begin{tabular}{lcccc}
\hline \multirow{2}{*}{ Espécies } & \multicolumn{4}{c}{ Posição na peça } \\
\cline { 2 - 5 } & 1 - Cerne Interno & 2 - Cerne Intermediário & 3 - Cerne Externo & 4 - Alburno \\
\hline 1 - Acácia & $8,01 \mathrm{Bb}$ & $6,52 \mathrm{Cc}$ & $9,88 \mathrm{Aa}$ & $5,92 \mathrm{Ca}$ \\
2 - Casuarina & $7,14 \mathrm{Bc}$ & $10,47 \mathrm{Aa}$ & $4,12 \mathrm{Cc}$ & $1,33 \mathrm{Dd}$ \\
3 -E. cloeziana & $4,41 \mathrm{Cd}$ & $5,50 \mathrm{Bb}$ & $6,28 \mathrm{Ab}$ & $1,60 \mathrm{Dd}$ \\
4 - Teca & $8,87 \mathrm{Ba}$ & $8,80 \mathrm{Bb}$ & $9,49 \mathrm{Aa}$ & $5,31 \mathrm{Cb}$ \\
5 -E. toreliana & $3,49 \mathrm{Ce}$ & $6,38 \mathrm{Ac}$ & $4,20 \mathrm{Bc}$ & $2,16 \mathrm{Dc}$ \\
\hline
\end{tabular}

Em que: As médias seguidas por uma mesma letra maiúscula, na horizontal, ou minúscula, na vertical, não diferem entre si (Scott-Knott; $\mathrm{p}>0,05)$.

deterioradas. Para o cerne externo, a acácia foi a menos resistente. Já para o alburno, as madeiras de acácia e casuarina foram as mais deterioradas. Os resultados apresentados estão em acordo com os dados de perda de massa, que revelaram ser a madeira de acácia a mais deteriorada e a de teca a mais resistente entre as testadas. Paes et al. (2007) ao estudarem a resistência natural de sete espécies, detectaram que a madeira de teca foi uma das mais resistentes ao cupins Nasutitermes corniger.

A quantidade de extrativos existente nas espécies foi analisada estatisticamente (Tabela 9). Verificou-se que os fatores posição, espécie e a interação posição $\mathrm{x}$ espécie foi significativa a $1 \%$ de probabilidade pelo teste de F. A interação foi desdobrada e analisada pelo teste de Scott-Knott a $5 \%$ de probabilidade (Tabela 10 ).

Observa-se na Tabela 10, que o teor de extrativos variou entre as espécies e dentro das espécies. As madeiras de acácia, eucalipto cloeziana e teca apresentaram os maiores teores de extrativos no cerne externo. Para a casuarina e eucalipto toreliana a maior proporção de extrativos foi detectada no cerne intermediário.

Dentre as espécies, a teca apresentou na posição 1 (cerne interno) o maior teor de extrativos e o eucalipto toreliana o menor. Na posição 2 (cerne intermediário), a casuarina apresentou o maior teor de extrativos e a acácia e o eucalipto toreliana os menores teores. No cerne externo, a acácia e a teca tiveram mais extrativos e a casuarina e o eucalipto toreliana os menores teores. No alburno, a acácia apresentou o maior teor de extrativos e as madeiras de casuarina e eucalipto cloeziana, os menores teores.

Observa-se (Tabelas 5 e 8) que a resistência das madeiras não esteve relacionada com o teor de extrativos existentes, pois nem sempre as madeiras mais resistentes apresentaram os maiores teores de extrativos.

\section{CONCLUSÕES}

A resistência natural das madeiras variou entre as espécies e nas posições dentro da peça no sentido medula-alburno. As madeiras do cerne 
foram mais resistentes que as do alburno em duas espécies (casuarina e teca), no entanto, no eucalipto cloeziana, o cerne interno foi mais atacado que o alburno.

No geral, as madeiras de teca e eucalipto toreliana foram mais resistentes que as demais ao cupim xilófago testado.

Os cupins atacaram mais severamente a acácia, que teve maior porcentagem de perda de massa, em alguns casos atingindo quase $50 \%$.

Aúnica madeira que teve relação direta entre a resistência da madeira e o teor de extrativos foi a teca, logo, de modo geral, a resistência das madeiras ensaiadas não esteve relacionada à quantidade de extrativos existentes nas mesmas.

\section{REFERÊNCIAS BIBLIOGRÁFICAS}

ALMEIDA, F. D. Propagação vegetativa de Eucalyptus cloeziana F. Muell. por estaquia e miniestaquia. 2006. 86 f. Dissertação (Mestrado em Ciência Florestal) - Universidade Federal de Viçosa, Viçosa, 2006.

AMERICAN SOCIETY FOR TESTING AND MATERIALS. ASTM D - 3345: standard method for laboratory evaluation of wood and other cellulosic materials for resistance to termite. Annual Book of ASTM Standard, Philadelphia, 2005. 3 p.

ANGELI, A. Tectona grandis (teca). Piracicaba: Instituto de Pesquisas e Estudos Florestais, 2003. Disponível em: <http://www.ipef.br/identificacao/ tectona.grandis.asp >. Acesso em: 19 abr. 2010.

ASSOCIAÇÃO BRASILEIRA TÉCNICA DE CELULOSE E PAPEL - ABTCP M6/68: Normas técnicas ABCP. São Paulo: ABTCP, 1974. 18 p.

BALIEIRO, F. C. et al. Acúmulo de nutrientes na parte aérea, na serapilheira acumulada sobre o solo e decomposição de filódios de Acacia mangium Willd. Ciência Florestal, Santa Maria, v. 14, n. 1, p. 59-65, 2004.

BARBOSA, R. I. Florestamento dos sistemas de vegetação aberta (Savanas/Cerrados) de Roraima por espécies exóticas (Acacia mangium Willd). Boa Vista: Conselho Estadual de Meio Ambiente, Ciência e Tecnologia de Roraima, 2002. 9 p. Disponível em: <http://agroeco.inpa.gov.br/ reinaldo/RIBarbosa_ProdCient

Usu_Visitantes/2002AcaciaTemasDiscussao_ CEMAT.pdf $>$. Acesso em: 22 abr. 2010.

CONSTANTINO, R. Chave ilustrada para identificação dos gêneros de cupins (Insecta: Isoptera) que ocorrem no Brasil. Papéis Avulsos de
Zoologia, São Paulo, v. 40, n. 25, p. 387-448, 1999. EMBRAPA FLORESTAS. 1 folder. [s. 1.]: Embrapa Florestas, 2004. Disponível em: <http://www. cnpf.embrapa.br/publica/folders/Teca_2004.pdf $>$. Acesso em: 19 abr. 2010.

FARIAS SOBRINHO, D. W.; PAES, J. B.; FURTADO, D. A. Tratamento preservativo da madeira de algaroba (Prosopis juliflora (Sw) D.C.), pelo método de substituição de seiva. Cerne, Lavras, v. 11, n. 3, p. 225-236, 2005.

FINDLAY, W. P. K. The nature and durability of wood. In: FINDLAY, W. P. K. (Ed). Preservation of timber in the tropics. Dordrecht: Matinus Nijhoff; Dr. W. Junk Publishrs, 1985. p. 1-13.

MOURA, V. P. G.; MELO, J. T.; SILVA, M. A. Comportamento de procedências de Eucalyptus cloeziana $\mathrm{F}$. Muell aos nove e meio anos de idade, em Planaltina, DF, área de cerrado. Scientia Forestalis, Piracicaba, n. 46, p. 52-62, 1993.

PAES, J. B. Resistência natural da madeira de Corymbia maculata (Hook.) K.D. Hill \& L.A.S. Johnson a fungos e cupins xilófagos, em condições de laboratório. Revista Árvore, Viçosa, MG, v. 26, n. 6, p. 761-767, 2002.

PAES, J. B. et al. Eficiência do óleo de candeia na melhoria da resistência da madeira de sumaúma a cupim xilófago. Cerne, Lavras, v. 16, n. 2, p. 217225, 2010.

PAES, J. B. et al. Resistência natural de sete madeiras ao cupim subterrâneo (Nasutitermes corniger Motsch.) em ensaio de preferência alimentar. Revista Brasileira de Ciências Agrárias, Recife, v. 2, n. 1, p. 57-62, 2007.

PAES, J.B.etal.Eficiênciadotratamentopreservativo na resistência da madeira de leucena (Leucaena leucocephala (Lam.) de Wit.) a organismos xilófagos. Revista Forestal Venezolana, Mérida, v. 52, n. 1, p. 85-91, 2008.

PAES, J. B. et al. Efeitos dos extrativos e cinzas na resistência natural de quatro madeiras a cupins xilófagos. Cerne, Lavras, v. 19, n. 3, p. 399-405, 2013.

PAES, J. B.; MORAIS, V. M.; LIMA, C. R. Resistência natural de nove espécies de madeiras do semi-áridobrasileiroa fungosxilófagos em condições de laboratório. Revista Árvore, Viçosa, MG, v. 28, n. 2, p. 275-282, 2004.

PAES, J. B.; VITAL, B. R. Resistência natural da madeira de cinco espécies de eucalipto a cupins subterrâneos em testes de laboratório. Revista Árvore, Viçosa, MG, v. 24, n. 1, p. 1-6, 2000.

PETTERSEN, R. C. Chemical composition of 
wood. In: ROWELL, R. (Ed.). The chemistry of solid wood. Washington: American Chemical Society, 1984. p. 54-126.

REMADE. Espécies de eucalipto. Revista da madeira, São Paulo, n. 59, 2001. Disponível em: $<$ http://www.remade.com.br/br/revistadamadeira ct $=$ Esp $\% \mathrm{C} 3 \%$ A 9 cies\&title $=$ Esp $\% \mathrm{C} 3 \% \mathrm{~A} 9 \mathrm{cies} \% 20$ de\%20Eucalipto>. Acesso em: 25 abr. 2010.

REMADE. Eucalipto: mercado aponta uso do eucalipto para móveis. Revista da Madeira, São Paulo, n. 103, 2007. Disponível em: <http:// www.remade.com.br/br/revistadamadeira_materia. php?num=1053\&Subject

$=$ Eucalipto $\&$ title $=$ Mercado $\% 20$ aponta $\% 20$ uso $\% 20$ do $\% 20$ eucalipto $\% 20$ para $\% 20 \mathrm{~m} \% \mathrm{~F} 3 \mathrm{veis}>$. Acesso em: 10 maio 2010.

RONDON, E. V. Estudo de biomassa de Tectona grandis L.f. sob diferentes espaçamentos no estado de Mato Grosso. Revista Árvore, Viçosa, MG, v. 30. n. 3, p. 337-341, 2006.

SCHIAVO, J. A.; MARTINS, M. A. Produção de mudas de acácia colonizadas com micorrizas e rizóbio em diferentes recipientes. Pesquisa Agropecuária Brasileira, Brasília, v. 38, n. 2, p. 173-178, 2003.

SILVA, L. M. et al. Inventário da arborização em duas vias de Mariópolis - PR. Revista da Sociedade Brasileira de Arborização Urbana, Piracicaba, v. 3, n. 1, p. 36-53, 2008.

SILVÉRIO, F. O. Metodologia de extração e determinação do teor de extrativos em madeiras de eucalipto. Revista Árvore, Viçosa, MG, v. 30, n. 6, p. 1009-1016, 2006.

STEEL, R. G. D.; TORRIE, J. H. Principles and procedures of statistic: a biometrical approach. 2 . ed. New York: Mc Graw Hill, 1980. 633p.

TSUKAMOTO FILHO, A. A. et al. Análise econômica de um plantio de teca submetido a desbastes. Revista Árvore, Viçosa, MG, v. 27, n. 4, p. 487- 494, 2003.

VEIGA, R. A. A.; CARVALHO, C. M.; BRASIL, M. A. M. Determinação de equações de volume para árvores de Acacia mangium. Cerne, Lavras, v. 6, n. 1, p. 103-107, 2000. 